\title{
Slugs (Arionidae) benefit from nocturnal artificial illumination
}

\author{
Roy H. A. van Grunsven (1) https://orcid.org/0000-0001-8873-1024, David Jähnichen, Maja Grubisic (1) \\ https://orcid.org/0000-0001-5410-8867, Franz Hölker 는 https://orcid.org/0000-0001-5932-266X
}

DOI

10.1002/jez.2170

\section{Original publication date}

14 May 2018

Document version

Accepted version

\section{Published in}

Journal of Experimental Zoology Part A: Ecological and Integrative Physiology

\section{Citation (Vancouver)}

van Grunsven RHA, Jahnichen D, Grubisic M, Holker F. Slugs (Arionidae) benefit from nocturnal artificial illumination. Journal of Experimental Zoology Part A: Ecological and Integrative Physiology. 2018;329(8-9):429-33. 


\section{Slugs (Arionidae) benefit from nocturnal artificial illumination}

Roy H. A. van Grunsven ${ }^{\mathrm{*}}$

David Jähnichen ${ }^{a, b}$

Maja Grubisic ${ }^{a, c}$

Franz Hölker

a Leibniz-Institute of Freshwater Ecology and Inland Fisheries (IGB), Müggelseedamm 301/310, 12587

Berlin, Germany

b Institute of Biochemistry and Biology, University of Potsdam, Karl-Liebknecht-Straße 24-25, 14476 Potsdam, Germany

c Institute of Biology, Freie Universität Berlin, Schwendenerstraße 1, 14195 Berlin, Germany

Figures: 1

Tables: 1

Running title: Slugs increase under artificial light

*Correspondence to: Roy van Grunsven, mail@royvangrunsven.nl

Current address: Dutch Butterfly Conservation PO-Box 5066700 AM Wageningen The Netherlands.

Tel: +31317467346

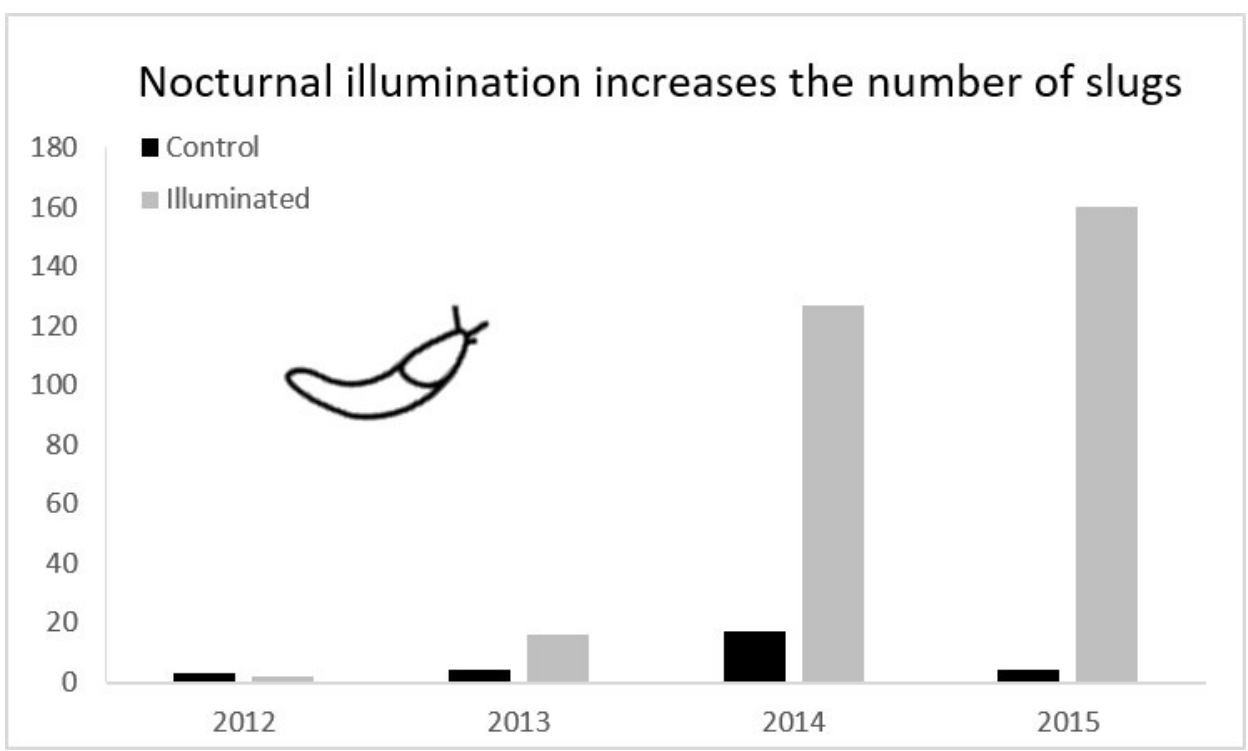




\section{Abstract}

Artificial illumination increases around the globe and this has been found to affect many groups of organisms and ecosystems. By manipulating nocturnal illumination using one large experimental field site with 24 streetlights and one dark control, we assessed the impact of artificial illumination on slugs over a period of four years. The number of slugs, primarily Arionidae, increased strongly in the illuminated site but not on the dark site. There are several non-exclusive explanations for this effect, including reduced predation and increased food quality in the form of carcasses of insects attracted by the light. As slugs play an important role in ecosystems and are also important pest species, the increase of slugs under artificial illumination can not only affect ecosystem functioning but also have important economic consequences.

Keywords: ALAN, Arionidae, Gastropoda, Light pollution, Phototaxis

Highlights: Experimental illumination of an experimental field resulted in a strong increase in the abundance of slugs, Arionidae. This is possibly a result of increased food quality.

Supporting grants: Federal Ministry of Education and Research, Germany (BMBF-033L038A). Federal Agency for Nature Conservation, Germany (3514821700). 


\section{Introduction}

The recent increase in artificial light at night (ALAN) and the consequent loss of natural nocturnal darkness (Kyba et al., 2017; Hölker et al., 2010) impact many organisms, both diurnal and nocturnal. The scientific interest in ecological impacts of this change has been increasing, with the majority of studies focusing on organisms such as moths, birds, sea turtles and bats, and to a less extent other invertebrates, plants, algae and fish (Gaston et al., 2015). To date, a group that has received very little attention is that of terrestrial mollusks, slugs and snails. For example, Davies et al (2012) reported no effect of the proximity of street lighting on the number of terrestrial mollusks (slugs and snails) in their samples. Terrestrial gastropods are to a large extent nocturnal or crepuscular and have important ecological functions (South, 2012). For example, snails and slugs are important generalist feeders in many terrestrial ecosystems. Slugs feed on a wide range of plant species and can impact total plant biomass and species diversity through selective grazing (Buschmann et al., 2005). Overall slugs thus play an ambivalent role in social-ecological systems. On the one side they are well-known pests in agricultural fields and gardens (South, 2012) while on the other they play a major role in decomposition, enhancing the rate of carbon mineralization (Theenhaus and Scheu, 1996).

We investigated the impact of artificial illumination on the abundance and composition of a slug population using a long term experimental field study in a rural area (Holzhauer et al., 2015). Slugs are the dominant mollusks and important herbivores in this ecosystem. The experimental approach allowed us to investigate the impacts of ALAN in a natural setting including a complete food web, which was not feasible in a laboratory or mesocosm study. Furthermore, this allowed us to study long term effects of ALAN exposure, as the experimental illumination has been running since 2012 . While short term responses to ALAN, such as attraction to light (van Langevelde et al., 2011), avoidance of light (Spoelstra et al., 2017), disruption of circannual rhythms (van Geffen et al., 2014), circadian timing (de Jong et al., 2016), and changes in physiology (Durrant et al., 2015) are known to occur, we focused on long term effects of ALAN on populations, as these are less frequently studied. Long term effects on a taxon that strongly impacts ecosystem processes, such as slugs, can have substantial consequences for ecosystem functioning.

ALAN can have direct and indirect effect on slugs. Slugs are known to be negatively phototactic (Zieger et al., 2009) and therefore might avoid the use of illuminated habitats at night. Some predators of slugs are also light avoiding (such as hedgehogs and slow worms), while others (for example carabid beetles) are visual hunters and might benefit from the increased visibility of slugs under ALAN. Therefore, the indirect effects of ALAN through predation might either increase or decrease slug abundance, depending 
on the dominant predator in the ecosystem and its response to nocturnal illumination. Another way that ALAN could indirectly influence slugs is through altered food availability. Slugs are generalist feeders that feed on living, senescent and dead plant and animal matter. ALAN may alter food quality of plants by altering plant phenology (Bennie et al., 2016), and change the availability of (dead) insects/insect material through plants-mediated interactions (Bennie et al., 2015) and positive insect phototaxis (Manfrin et al., 2017). Therefore, ALAN can impact slugs in several non-exclusive ways. It is not clear which impacts would prevail in a natural setting and how this would reflect on the whole ecosystem. Whether slugs are able to adapt to long-term exposure to ALAN is also not known.

\section{Materials and Methods}

Sampling site and experimental design

The study was conducted in the Westhavelland Nature Park, located ca. $70 \mathrm{~km}$ northwest of Berlin, in Brandenburg, Germany. The park has little artificial nocturnal illumination and has been classified as an "International Dark-Sky Reserve" by the International Dark-Sky Association (International Dark Sky Association, 2015).

In a managed grassland area, two study sites were installed along a drainage ditch at 600m distance from each other. The sites consist of 12 street lights each that were positioned in a grid $(60 \mathrm{~m} \times 40 \mathrm{~m})$, in 3 parallel rows with $20 \mathrm{~m}$ spacing between the lights and each of the rows. Lights were installed in 2012 and have been continuously running since July 25, 2012 as a part of the long-term data collection program described in detail in Holzhauer et al. (2015). The two sites were managed in an identical manner (e.g. mowing, flow regulations) to minimize variation in potential confounding factors of ALAN and allow for quantitative comparison of data. The lights were equipped with $70 \mathrm{~W}$ high-pressure sodium lamps (VIALOX NAV-T Super 4Y, yellow 2000 K, Osram, Munich, Germany) from July 25, 2012 until June 17, 2015, and with 51 W white LED lamps (TECEO 1, 32 LEDs, neutral white 4000K, Schréder, Brussels, Belgium) from June 17, 2015 onwards. The lights were designed to produce similar intensity, 119.4 ( \pm 7.6$)$ lux at 1.5 meter height directly underneath the lamp for HPS and $119.6( \pm 7.2)$ lux for LED. The spectral composition of the lights was measured using a compact spectrometer (specbos 1211, JETI, Jena, Germany) (Supplement 1). In the illuminated site, the lights were switched on at the beginning of the civil twilight and switched off at the end of civil twilight using an automatic time switch. In the control site the lights were kept off at all times.

In both the illuminated and control site 24 pitfall traps were deployed for one night and the consecutive day once a month from May till October from 2012 until 2015 (see Holzhauer et al. (2015). Nights with 
half-moon were selected for trapping. The pitfall traps were positioned in between and underneath the lights resulting in light levels at the traps of approximately 1 lux for the traps furthest from the light, to 50 lux for traps directly underneath the lights. A receptacle filled with alcohol was placed in the trap at sunset, replaced by a new receptacle at sunrise, which was then collected at sunset resulting in a nocturnal and a diurnal sample. Catches were brought to the lab and identified to family using Bogon (1990) and Kerney et al. (1983).

Analysis

The catches of the individual traps were summed per sampling event per site, resulting in one nocturnal and one diurnal catch value per site per month. Nocturnal and consecutive diurnal catches were analyzed together as a total catch per sampling event per site. To separate direct effects of ALAN on the activities of slugs (measurable from nocturnal catches) from indirect effects (measurable from the diurnal catches), we analyzed diurnal and nocturnal data separately in addition to analyzing the total catch. Data was analyzed using negative binomial models using package Ime4 (Bates, 2010) for $R$ ( $R$ Core Team, 2016) with factors 'treatment' and 'year' and their interaction, and 'month' as a random factor.

\section{Results}

The community of slugs was dominated by Arionidae (Arion sp.) with low numbers of Agriolimicidae (Deroceras sp.) and Boetgerillidae (Boetgerilla pallens) (Table 1). The total number of slugs (nocturnal and diurnal catches combined) increased both in illuminated and control site, but the increase was significantly higher at the illuminated site over the sampled years (treatment $x$ year: $Z=2.81$, $p=0.0049)$ (Fig. 1). There was a significant effect of treatment $(Z=2.47, p=0.014)$ but not year $(Z=1.19, p=0.23)$. For the diurnal catches, there was a significant interaction between treatment and year $(Z=3.22, p=0.0013)$ and a significant difference between the two treatments $(Z=2.87, P=0.004)$, but not between years $(Z=0.044, p=0.96)$. For the nocturnal catches, no differences were found between the treatments $(Z=1.26, p=0.21)$ nor years $(Z=1.362, p=0.17)$, and there was no significant interaction (treatment $x$ year: $Z=1.51, p=0.13$ ). The maximum number of slugs caught in a single trap per month was 1 in 2012, 2 in 2013, 23 in 2014 and 23 in 2015.

\section{Discussion:}

Over multiple years, the total number of slugs (predominantly Arionidae) increased over time in the field that experienced ALAN, while no increase was observed at the control field. Given that other environmental conditions and management practices did not change in this period and did not differ 
between the fields (Holzhauer et al., 2015) and the impact of weather fluctuations was expected to be similar at both sites due to their proximity (ca. 600m Euclidian distance), we believe that the difference in ALAN is the main factor to explain this result. However, due to the limitation of the experimental setup with only one field per treatment, strictly speaking we cannot rule out that something other than the light treatment has caused the observed pattern. However, given the similarity between the fields and the fact that the number of slugs was nearly identical at the start of the experiment, we consider it very likely that the observed pattern is a response to the illumination. The increase in catches over time was significant for the diurnal catches, but not for nocturnal, indicating that these are a result of indirect effects of ALAN, and not merely an increase in activity as a direct response to light exposure. A positive phototaxis of slugs from surrounding areas to the light sources would have resulted in an increase in nocturnal catches at the illuminated site. Given the light avoiding behavior of slugs (Zieger et al 2009) and the long period over which the increases in slug abundance are recorded ( 3 years), we believe that the contribution of this effect is likely small. Slugs are notorious for moving slowly, crossing 10.8 meters per day on average (Grimm and Schaumberger, 2002). Furthermore, negative phototaxis or light avoidance would have resulted in the opposite pattern, lowering the number of catches at the illuminated site. Dainton (1954) showed that when exposed to illumination, previously dark-adapted slugs show a short-term increase in activity, followed by a relatively quick adaptation to light and return to normal activity levels within an hour. This indicates that slugs express neither positive nor negative phototaxis to long-lasting illumination, and that our results likely cannot be explained by changes in the nocturnal activity patterns of slugs. It is possible that the increase in numbers observed is the result of increased reproduction. Producing large numbers of eggs and being hermaphroditic Arionidae can show rapid population growth (South, 2012). Our result seems contradictory to that of Davies et al. (2012) that reported no effect of ALAN on gastropods. This might be because they analyze gastropods as whole and it is to expect that in such a diverse group different responses to artificial light can be found. In our case the pattern is caused by Arionid slugs and we do not know whether these were present in the experiment of Davies et al. (2012).

It is not clear how ALAN could affect the diurnal activity of slugs. Slugs are mostly active at night and individual species differ at the timing of their nocturnal activity, but the onset of activity does not necessarily coincide with the onset of darkness (Dainton, 1954). Diurnal activity is regulated by both endogenous and exogenous factors, especially light, temperature and season (Daxl, 1969). Lewis (1969) showed that in Arion ater the circadian rhythm of locomotor activity persists also under constant illumination, although it was out of phase with normal light-dark sequence. Kumar and Babu (1978) 
showed that light acted as a zeitgeber for locomotor rhythms in the slug Laevicaulis alte, while in constant light and dark conditions the slugs exhibited a continuous pattern of activity.

There are several other mechanisms that could be involved in this effect. ALAN could have reduced predation pressure on slugs. Visual predators, such as carabid beetles, slow worms and hedgehogs could be expected to be more effective under nocturnal illumination, resulting in a decrease of slugs at the illuminated site. Here, however, the opposite pattern was observed. If these predators themselves would avoid light, releasing slugs from predation pressure might explain the observed increase in slugs to some extent. However, hedgehogs and slow worms were absent or very rare in this area (pers. observation), and carabid beetles declined in numbers at the illuminated site (Manfrin et al., 2017). This moderate decrease in predators is unlikely to have such a strong effect on the number of slugs alone. In addition, ALAN may have increased food availability and quality. ALAN attracts insects from the surrounding area, many of which stay trapped flying around the lights until they die of exhaustion (Eisenbeis, 2006; Manfrin et al., 2017). Dead insects that fall on the ground are a nitrogen-rich food source for slugs and other scavengers. The night-active scavenger carrion beetle, Silpha sp., showed increased activity at night and day under ALAN conditions (Manfrin et al., 2017) and clearly benefited from the presence of exhausted or dead insects that were attracted to the lights the night before. Increased input of insect material may have benefited slugs under ALAN conditions as well. Furthermore, ALAN may have potentially increased nutritional quality and quantity of plant matter (Bennie et al., 2015). These effects were not assessed in our study, but cannot be excluded.

ALAN-induced responses of slugs could be of basic interest for farmers and gardeners. In both ornamental and vegetable gardens slugs of the family Arionidae are among the most problematic pests damaging or consuming many plants and crop seedlings (Gregory and Musick, 1976). With the rising popularity of small solar-powered LED lights, more and more gardens have nocturnal light sources that are kept on the whole night throughout the year. If illumination increases the abundance of slugs, the use of ornamental illumination in gardens could contribute to the numbers and impact of these pests, and stimulate the use of pesticides with potential consequences for other organisms (Saad et al., 2017). It is likely that the spectral composition of the light plays a role in determining this effect, as the sensitivity of slugs and other organisms is wavelength-dependent (Davies et al., 2013). In this study two different light sources were used, but as they were sequentially applied, their effects cannot be distinguished. The knowledge needed to distinguish effects of different light spectra on slugs is currently lacking. 
Slugs play an important ecological role in terrestrial ecosystems. As they are relatively large for species feeding on dead plant matter, by increasing decomposition they can have a substantial impact on carbon and nutrient cycling and alter soil nutrient dynamics (Theenhaus and Scheu, 1996). Therefore, an increase in the density of slugs is likely to impact ecosystem functions. Nocturnal illumination continues to increase worldwide (Kyba et al., 2017) and impacts of this pervasive change on ecosystem functioning and ecosystem services have yet to be understood. Mounting evidence reports effects on different groups, communities and ecosystem processes (Gaston et al., 2015) and this study adds to this knowledge. It is becoming evident that ALAN affects many aspects and processes in illuminated ecosystems and further studies are needed to understand how these connect and interact in both natural and intensively managed ecosystems.

\section{Acknowledgements:}

The experimental sites were installed within the interdisciplinary research project "Verlust der Nacht" (Loss of the Night) which was supported by the Federal Ministry of Education and Research, Germany (BMBF-033L038A). The study has also been supported by the Federal Agency for Nature Conservation, Germany (3514821700). MG was supported by IGB Equal opportunity fund for young female scientists and the Freie Universität Berlin - Dahlem Research School HONORS fellowship. We thank Stefan Heller, Nina Weiß and Alessandro Manfrin for their help with fieldwork and Sybille Schroer for the pivotal role she played in the "Verlust der Nacht" research projects. 


\section{References:}

Bates DM. 2010. Lme4: Mixed-effects modeling with r. URL http://Ime4 r-forge r-project org/book.

Bennie J, Davies TW, Cruse D, Gaston KJ. 2016. Ecological effects of artificial light at night on wild plants. J Ecol.

Bennie J, Davies TW, Cruse D, Inger R, Gaston KJ. 2015. Cascading effects of artificial light at night: Resourcemediated control of herbivores in a grassland ecosystem. Philos Trans R Soc B 370:20140131.

Bogon K. 1990. Landschnecken. Biologie-ökologie-biotopschutz. Augsburg: Natur Verlag. [in

Buschmann H, Keller M, Porret N, Dietz H, Edwards P. 2005. The effect of slug grazing on vegetation development and plant species diversity in an experimental grassland. Funct Ecol 19:291-298.

Dainton BH. 1954. The activity of slugs. J Exp Biol 31:188-197.

Davies TW, Bennie J, Gaston KJ. 2012. Street lighting changes the composition of invertebrate communities. Biol Lett 8:764-767.

Davies TW, Bennie J, Inger R, Ibarra NH, Gaston KJ. 2013. Artificial light pollution: Are shifting spectral signatures changing the balance of species interactions? Global Change Biol 19:1417-1423.

DaxI R. 1969. Beobachtungen zur diurnalen und saisonellen aktivität einiger nacktschneckenarten. $Z$ angew Zool 56:357-370.

de Jong M, Jeninga L, Ouyang JQ, van Oers K, Spoelstra K, Visser ME. 2016. Dose-dependent responses of avian daily rhythms to artificial light at night. Physiol Behav 155:172-179.

Durrant J, Michaelides EB, Rupasinghe T, Tull D, Green MP, Jones TM. 2015. Constant illumination reduces circulating melatonin and impairs immune function in the cricket teleogryllus commodus. Peer] 3:e1075.

Eisenbeis G. 2006. Artificial night lighting and insects: Attraction of insects to streetlamps in a rural setting in germany. Ecological consequences of artificial night lighting. Washington DC: Island press.

Gaston KJ, Visser ME, Hölker F. 2015. The biological impacts of artificial light at night: The research challenge. Philos Trans R Soc B 370.

Gregory WW, Musick GJ. 1976. Insect management in reduced tillage systems 11 approved by associate director of the ohio agricultural research and development center as journal article no. 81-76. Received for publication april 1, 1976. Bulletin of the ESA 22:302-304.

Grimm B, Schaumberger K. 2002. Daily activity of the pest slug arion lusitanicus under laboratory conditions. Ann Appl Biol 141:35-44.

Hölker F, Wolter C, Perkin EK, Tockner K. 2010. Light pollution as a biodiversity threat. Trends in Ecology and Evolution 25:681-682

Holzhauer SIJ, Franke S, Kyba CCM, Manfrin A, Klenke R, Voigt CC, Lewanzik D, Oehlert M, Monaghan MT, Schneider S, Heller S, Kuechly H, Bruning A, Honnen AC, Holker F. 2015. Out of the dark: Establishing a large-scale field experiment to assess the effects of artificial light at night on species and food webs. Sustainability 7:15593-15616.

International Dark Sky Association. 2015. International dark sky reserves: Westhavelland (germany).

Kerney MP, Cameron RA, Jungbluth JH. 1983. Die landschnecken nord-und mitteleuropas.

Kumar TP, Babu KS. 1978. Diurnal variations in cholinesterase activities in the slug, laevicaulis alte. Cell Mol Life Sci 34:612-613.

Kyba CC, Kuester T, de Miguel AS, Baugh K, Jechow A, Hölker F, Bennie J, Elvidge CD, Gaston KJ, Guanter L. 2017. Artificially lit surface of earth at night increasing in radiance and extent. Science advances 3:e1701528

Lewis R. 1969. Studies on the locomotor activity of the slug arion ater (linnaeus). I. Humidity, temperature and light reactions. Malacologia 7:295-306.

Manfrin A, Singer G, Larsen S, Weiss N, van Grunsven RH, Weiss N-S, Wohlfahrt S, Monaghan MT, Hölker F. 2017. Artificial light at night affects organism flux across ecosystem boundaries and drives community structure in the recipient ecosystem. Frontiers in Environmental Science 5:61.

R Core Team. 2016. R: A language and environment for statistical computing [internet]. 2014. Vienna (austria): R foundation for statistical computing.

Saad A, Ismail S, Dahalan F. 2017. Metaldehyde toxicity: A brief on three different perspectives. Journal of Civil Engineering 8.

South A. 2012. Terrestrial slugs: Biology, ecology and control: Springer Science \& Business Media. [in

Spoelstra K, van Grunsven RH, Ramakers JJ, Ferguson KB, Raap T, Donners M, Veenendaal EM, Visser ME. Response of bats to light with different spectra: Light-shy and agile bat presence is affected by white and green, but not red light; 2017. The Royal Society. p 20170075.

Theenhaus A, Scheu S. 1996. The influence of slug (arion rufus) mucus and cast material addition on microbial biomass, respiration, and nutrient cycling in beech leaf litter. Biol Fertility Soils 23:80-85.

van Geffen KG, van Grunsven RHA, van Ruijven J, Berendse F, Veenendaal EM. 2014. Artificial light at night causes diapause inhibition and sex-specific life history changes in a moth. Ecology and Evolution 4:2082-2089.

van Langevelde F, Ettema JA, Donners M, WallisDeVries MF, Groenendijk D. 2011. Effect of spectral composition of artificial light on the attraction of moths. Biol Conserv 144:2274-2281.

Zieger MV, Vakoliuk IA, Tuchina OP, Zhukov VV, Meyer-Rochow VB. 2009. Eyes and vision in arion rufus and deroceras agreste (mollusca; gastropoda; pulmonata): What role does photoreception play in the orientation of these terrestrial slugs? Acta Zoologica 90:189-204. 
Table 1

\begin{tabular}{l|cccc|cccc} 
& \multicolumn{5}{|c|}{ dark site } & \multicolumn{4}{c}{ illuminated site } \\
\multicolumn{1}{c|}{ day/night } & 2012 & 2013 & 2014 & 2015 & 2012 & 2013 & 2014 & 2015 \\
\hline Agriolimacidae & $2 * / 1$ & $1 / 3$ & $3 / 10$ & $0 / 0$ & $0 / 2 *$ & $1 / 6$ & $2 / 2$ & $0 / 2$ \\
Arionidae & $0 / 0$ & $0 / 0$ & $1 / 3$ & $1 / 2$ & $0 / 0$ & $4 / 5$ & $49 / 74$ & $68 / 80$ \\
Boettgerilla & $0 / 0$ & $0 / 0$ & $0 / 0$ & $0 / 2$ & $0 / 2$ & $0 / 0$ & $0 / 0$ & $0 / 0$
\end{tabular}

Table 1 the number of individuals per family caught in the pit fall traps per field and per year separated in nocturnal and diurnal catches. (* In both sites one individual was caught before the light was switched on.)

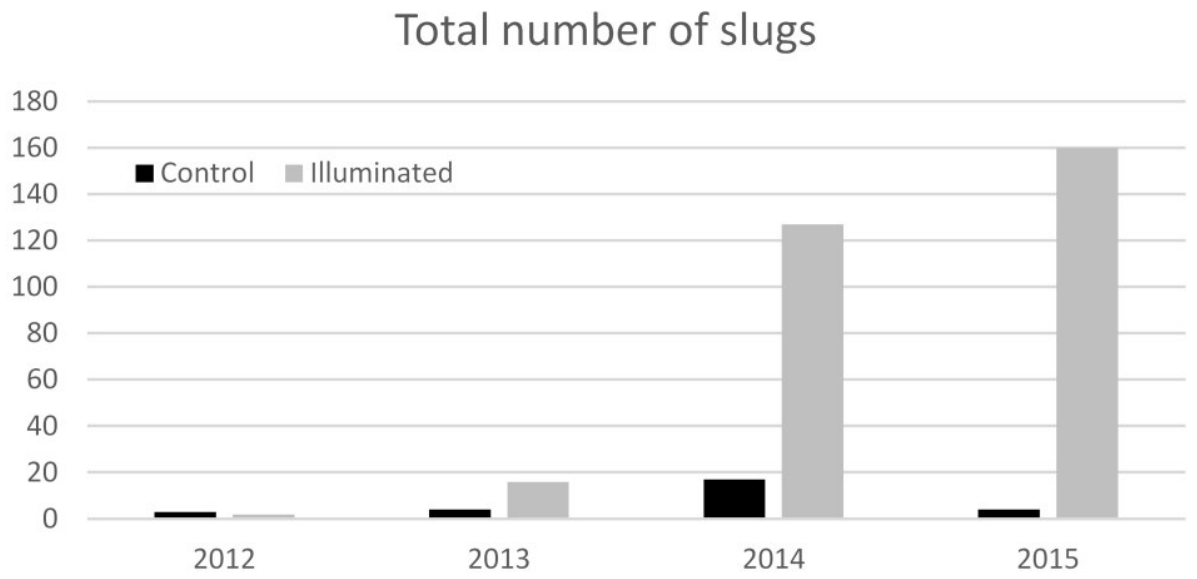

Figure 1 Total number of slugs caught per year for the illuminated and control site, diurnal and nocturnal catches combined.

\section{Supplement 1}

Relative spectral composition of both light sources used, measured with a Specbos 1211, JETI, Jena, Germany. 